\title{
Edge-chipping reduction in rotary ultrasonic machining of ceramics: finite element analysis and experimental verification
}

\author{
Z.C. Li ${ }^{a}$, Liang-Wu Cai ${ }^{b}$, Z.J. Pei ${ }^{{ }^{*}}$, C. Treadwell ${ }^{\mathrm{c}}$ \\ ${ }^{a}$ Department of Industrial and Manufacturing Systems Engineering, Kansas State University, \\ Manhattan, KS 66506, USA \\ ${ }^{\mathrm{b}}$ Department of Mechanical and Nuclear Engineering, Kansas State University, \\ Manhattan, KS 66506, USA \\ ${ }^{\mathrm{c}}$ Sonic-Mill, 7500 Bluewater Road N.W., Albuquerque, NM 87121, USA \\ This paper published as: Li, Z.C., Cai, L.W., Pei, Z.J., and Treadwell, C., 2006, "Edge-chipping \\ reduction in rotary ultrasonic machining of ceramics: finite element analysis and experimental \\ verification," International Journal of Machine Tools and Manufacture, Vol. 46, No. 12-13, pp. \\ 1469-1477.
}

\begin{abstract}
Rotary ultrasonic machining (RUM) is one of the machining processes for advanced ceramics. Edge chipping (or chamfer), commonly observed in RUM of ceramic materials, not only compromises geometric accuracy but also possibly causes an increase in machining cost. In this paper, a three-dimensional finite element analysis (FEA) model is developed to study the effects of three parameters (cutting depth, support length, and pretightening load) on the maximum
\end{abstract}

\footnotetext{
* Corresponding author. Tel.: +1 785532 3436; fax: +1 7855323738.

E-mail address: zpei@ksu.edu (Z.J. Pei).
} 
normal stress and von Mises stress in the region where the edge chipping initiates. Two failure criteria (the maximum normal stress criterion and von Mises stress criterion) were used to predict the relation between the edge chipping thickness and the support length. Furthermore, a solution to reduce the edge chipping is proposed based upon the FEA simulations and verified by experiments.

Keywords: Ceramic; Edge chipping; Finite element analysis; Grinding; Machining; Rotary ultrasonic machining

\section{Introduction}

Advanced ceramics are increasingly utilized in industries such as aerospace, automotive, and cutting tools. Their mechanical properties (such as high hardness, excellent wear resistance, and high-temperature stability) result in superior performances. These very properties are also responsible for difficulties encountered in machining them into desired shapes and dimensions. It was reported that the machining cost for ceramic components could be as high as $90 \%$ of the total cost [1]. Therefore, there is a crucial need to develop more cost-effective machining processes for ceramic components.

Rotary ultrasonic machining (RUM) is one of the processes applicable to ceramic materials. It has the potential to achieve high material removal rates while maintaining low cutting pressures, resulting in relatively low surface damage and strength degradation [2-3]. The RUM process is 
illustrated in Fig. 1. A rotating core drill with metal-bonded diamond abrasives is ultrasonically vibrated in its axial direction and fed towards the workpiece at a constant feedrate or a constant force. Coolant pumped through the core of the drill washes away the swarf, prevents jamming of the drill, and keeps it cool.

Since its inception in 1960s [4-5], many papers on RUM have been published. Pei et al. [6-7] reported that there exist two material removal modes in RUM of ceramic materials: brittle fracture mode and ductile model. Models for predicting the material removal rate (MRR) based upon the two material removal modes were developed by Prabhakar et al. [8] and Pei et al. [6,9]. Spur and Holl [10] and Zeng et al. [11] investigated tool wear mechanisms in RUM. Effects of RUM machining variables (spindle speed; feedrate; ultrasonic vibration amplitude and frequency; diamond type, size and concentration; bond type for the cutting tool; etc.) on the performances (MRR, cutting force, surface roughness, etc.) of RUM were investigated experimentally [2,12-17]. Extensions of RUM to face milling [18-19], disk grinding [20], and complex contour machining [21-22] were developed. RUM was also introduced into machining of ceramic matrix composites [23-24]. More information on RUM can be found in several review papers [25-28].

One of the remaining challenges for RUM is edge chipping (or, chamfer) [29-30]. Fig. 2 illustrates the edge chipping induced in the RUM process. Shown in Fig. 2(a) is a workpiece that has been machined into two pieces by RUM. One piece is the machined part with the desired hole, the other is a rod (or slug) removed from the workpiece. Fig. 2(b) shows the side view of the bottom portion of the machined rod. An edge burr around the bottom of the rod is observable. 
When the cutting tool nearly drills through the workpiece, the rod breaks off from the workpiece, causing the edge chipping around the hole exit edge as shown in Fig. 2(c). The edge chipping thickness can be measured either on the rod as sketched in Fig. 2(b), or on the hole exit as shown in Fig. 2(d).

The edge chipping in a machined ceramic component not only compromises geometric accuracy, but also causes possible failure of the component during service [31]. Generally, edge chipping is not acceptable on finished products, and has to be machined off by other processes after the RUM operation. The larger the edge chipping thickness, the higher the total machining cost. Therefore, research efforts to reduce the edge chipping thickness in RUM are desirable.

$\mathrm{Ng}$ et al. [31] characterized the edge chipping in ceramic milling into three categories: entrance edge chipping, interior edge chipping, and exit edge chipping. They reported that the microstructure and stress distribution were the key factors for the initiation and propagation of the edge chipping. Yoshifumi et al. [32] studied edge chipping in slot grinding of Mn-Zn ferrite. They concluded that the size of the edge chipping was proportional to the MRR. Based upon Chiu et al.'s work [33] on edge chipping initiation in milling of brittle materials, Cao [34] studied the factors related to exit edge chipping in milling of dental ceramics using a twodimensional (2-D) finite element analysis (FEA) model. In his model, a microcrack was used to simulate a critical flaw or pre-existing machining induced damage. His results revealed that the main influencing factors in determining the size of exit edge chipping were the size and length of the microcrack as well as the orientation and location of the applied load. 
The aforementioned investigations dealt with the machining induced edge chipping in milling and grinding of brittle materials. Little research on edge chipping in RUM has been reported. Jiao et al. [29] studied the edge chipping in RUM of ceramics using a combined experimental design and finite element method. They used the Withney-Nuismer point stress criterion (more information can be found in the literature about this criterion [35-36]) to predict edge chipping initiation. They reported that the main influencing factor on edge chipping was the cutting force, which, in turn, was determined by the controllable machining variables (such as spindle speed, ultrasonic vibration amplitude, and feedrate). They found that the edge chipping thickness could be reduced by using higher spindle speed and smaller feedrate due to reduced cutting forces. $\mathrm{Li}$ et al. [30] conducted a preliminary study on the initiation of edge chipping in RUM using a three-dimensional (3-D) FEA model. They used the von Mises stress failure criterion to predict edge chipping initiation. They found that the cutting depth and the support length had significant effects on edge chipping initiation. But, they did not report any practical ways to reduce the edge chipping thickness. The literature review conducted by the authors has revealed the lack of a practical solution to reduce the edge chipping in RUM of ceramics.

In this paper, a 3-D FEA model for RUM is developed to investigate the effects of three parameters (cutting depth, support length, and pretightening load) on the maximum stresses (the maximum normal stress and von Mises stress) in the region where the edge chipping initiates. The FEA model is then used to study the relation between the edge chipping thickness and the support length. A possible solution to reduce the edge chipping thickness through increasing the support length is proposed and verified by experiments. 


\section{Development of the FEA model}

\subsection{Assumptions for edge chipping initiation}

The FEA model in this study only concerns the static stress distribution in the region where edge chipping initiates. The dynamic component of the material removal process is not taken into account. As shown in Fig. 1, it is assumed that the edge chipping will initiate in a brittle fracture mode when the maximum stress satisfies the failure criterion. The edge chipping thickness predicted by the FEA model is the vertical distance between the location where the edge chipping initiates and the workpiece bottom surface. The two stress failure criteria used are the maximum normal stress criterion and von Mises stress criterion, two commonly used criteria applicable to isotropic materials [37].

Based on the maximum normal stress criterion, edge chipping is assumed to initiate if $\sigma \geq \sigma_{u t}$ where $\sigma$ is the maximum principle stress obtained from the FEA simulation and $\sigma_{u t}$ is the tensile strength of the workpiece material (listed in Table 1).

With the von Mises stress criterion, edge chipping is assumed to initiate when the von Mises equivalent stress reaches the tensile strength of the workpiece material. The von Mises equivalent stress is defined as: 
$\sigma_{e q}=\sqrt{\frac{\left(\sigma_{1}-\sigma_{2}\right)^{2}+\left(\sigma_{2}-\sigma_{3}\right)^{2}+\left(\sigma_{1}-\sigma_{3}\right)^{2}}{2}}$

where $\sigma_{1}, \sigma_{2}$, and $\sigma_{3}$ are stresses in the principle directions.

\subsection{Geometry and mesh design for the FEA model}

Three parameters to be studied are defined as follows (refer to Fig. 1). The cutting depth $\left(H_{C}\right)$ is the distance between the top surface of the workpiece and the horizontal machined surface, ranging from 0 to $6.30 \mathrm{~mm}$. The support length $(L)$ is the radial length of the contact area between the workpiece and the fixture, ranging from 3 to $11 \mathrm{~mm}$. The pretightening load $\left(F_{P}\right)$ is the pressure applied on the top surface of the workpiece to tighten the workpiece, ranging from 3 to $15 \mathrm{MPa}$.

A commercial software (ANSYS 7.0) was used to develop the FEA model. The 3-D FEA model of the workpiece was constructed using axisymmetric eight-node quadrilateral elements. The mesh is shown in Fig. 3. The elements are refined progressively near the region where the edge chipping initiates. The workpiece is assumed to have a cylinder shape with a radius of 16 $\mathrm{mm}$ and thickness of $6.30 \mathrm{~mm}$.

\subsection{Boundary conditions}

Due to the symmetry of the workpiece and fixture, one half of the workpiece was modeled in the axisymmetric plane, as shown in Fig. 4. The workpiece was modeled as a rectangle with a rectangular recess. The workpiece was constrained in the $y$-direction on the bottom surface over the support length $L$. The axisymmetric line of the workpiece was constrained in the $x$-direction. 
A uniformly distributed pressure $\left(F_{P}\right)$ was applied on the top surface of the workpiece over a length equal to the support length $L$.

The contact area (with a length of $l$ ) between the tool end surface and the horizontal machined surface in the workpiece consists of a left fillet contact region, a middle horizontal contact region, and a right fillet contact region. Both of the two fillet contact regions were modeled with a fillet radius of $0.1 \mathrm{~mm}$ (approximately equal to the "nose radius" of the end face of the cutting tool). A uniformly distributed pressure $\left(F_{C}=15 \mathrm{MPa}\right.$, a typical value for the grinding force in the tool axial direction when rotary ultrasonic machining of the workpiece material used for this study) was applied on the middle horizontal contact region. A linearly varying pressure, whose value ranged from zero at the vertical edge to $F_{C}$ at the horizontal edge, was applied on both fillet contact regions, as shown in Fig. 4.

\section{Results of FEA simulations}

\subsection{Stress distributions}

Fig. 5 shows the distributions of the maximum normal stress and the von Mises stress in the region of edge chipping initiation when $H_{C}=5 \mathrm{~mm}, L=8 \mathrm{~mm}$, and $F_{P}=3.7 \mathrm{MPa}$. It can be seen that both of the maximum normal stress and the von Mises stress increase significantly as the distance to the fillet decreases. The maximum values of the two stresses occur on the fillet.

\subsection{Effects of the three parameters on the maximum stresses}


Figs. 6-8 show the effects of the three parameters (cutting depth $H_{C}$, pretightening load $F_{P}$, and support length $L$ ) on the maximum values of the maximum normal stress and the von Mises stress. Fig. 6 shows that the maximum values of the maximum normal stress and the von Mises stress nonlinearly increase as the cutting depth increases. Fig. 7 shows the effects of the pretightening load. It can be seen that, as the pretightening load increases, the maximum values of the two stresses increase slightly. From Fig. 8, it can be seen that, as the support length increases from 3 to $10 \mathrm{~mm}$, the maximum values of the two stresses decrease slightly. When the support length exceeds $10 \mathrm{~mm}$, sharp decreases in the maximum values of the two stresses can be observed. This indicates that increasing the support length can reduce the maximum values of the two stresses. In this way, the edge chipping initiation can be postponed so that the edge chipping thickness can be reduced.

\subsection{Relation between edge chipping thickness and support length}

The procedure to estimate the edge chipping thickness using the maximum normal stress criterion is as follows. For each value of the support length, a curve is plotted with the maximum value of the maximum normal stress versus the cutting depth. Based on the maximum normal stress criterion, the critical cutting depth where the edge chipping initiates $\left(\sigma \geq \sigma_{u t}\right)$ can be found. For the workpiece with the thickness of $6.30 \mathrm{~mm}$, the edge chipping thickness can be calculated by subtracting the critical cutting depth from the workpiece thickness. For example, when the support length $L=10.5 \mathrm{~mm}$, the critical cutting depth will be $5.47 \mathrm{~mm}$. Hence, the 
edge chipping thickness $=6.30-5.47=0.83 \mathrm{~mm}$. A similar procedure was used to estimate the edge chipping thickness based upon the von Mises stress criterion.

The relation between the support length and the edge chipping thickness predicted from the FEA simulations is shown in Fig. 9. As the support length increases from 4.5 to $10.5 \mathrm{~mm}$, the edge chipping thickness decreases from 0.86 to $0.83 \mathrm{~mm}$ when the maximum normal stress criterion is used, and decreases from 0.80 to $0.79 \mathrm{~mm}$ when the von Mises stress criterion is used.

\section{Experimental verification}

\subsection{Experimental set-up and conditions}

A series of RUM tests have been conducted to verify the predicted relation between the support length and edge chipping thickness. In RUM operation, a blind hole is usually drilled in the fixture under the workpiece to receive the rod, as shown in Fig. 1. The support length is determined by the diameter of the blind hole. To verify the effects of support length, three blind holes with diameters of 23,16, and $11 \mathrm{~mm}$, respectively, were drilled in the fixture. Accordingly, three different support lengths of $4.5,8$, and $10.5 \mathrm{~mm}$ can be achieved. For each support length, RUM test was repeated three times. 
The RUM tests were performed on an ultrasonic machine of Sonic Mill Series 10 (Sonic-mill ${ }^{\circledR}$, Albuquerque, NM, USA). For the metal-bonded diamond core drill (N.B.R. Diamond Tool Corp., LaGrangeville, NY, USA), the outer and inner diameters were 9.64 and $7.72 \mathrm{~mm}$, respectively. The mesh size was from 80 to 100 . The dimension of the workpieces $\left(92 \% \mathrm{Al}_{2} \mathrm{O}_{3}\right.$ sintered) (Ferro-ceramic Grinding, Inc., Wakefield, MA, USA) was $32 \mathrm{~mm} \times 32 \mathrm{~mm} \times 6.30 \mathrm{~mm}$. Properties of the workpiece material are listed in Table 1. Mobilemet ${ }^{\circledR}$ S122 water-soluble cutting oil (MSC Industrial Supply Co., Melville, NY, USA) was used as coolant (diluted with water by 1 to 20 ratio). Other RUM conditions are listed in Table 2 .

\subsection{Measurement of edge chipping thickness}

A digital video microscope (Olympus DVM-1, Olympus America, Inc., Melville, NY, USA) was utilized to inspect the chipping at the hole exit edge. A vernier caliper was used to measure the edge chipping thickness on the rod, as sketched in Fig. 2(b).

\subsection{Experimental results and discussion}

The experimental results are summarized in Table 3. It can be seen that the edge chipping thickness decreases as the support length increases. The experimental relation between the support length and the edge chipping thickness is also plotted in Fig. 9. As the support length increases, the edge chipping thickness decreases. This trend agrees well with that predicted from the FEA simulations. 
However, there are differences between the FEA simulations and experimental results. One difference is in the absolute values of the chipping thickness, the other is in the slopes of the curves (or, the degrees of the effects of the support length on the chipping thickness). Possible reasons for such differences could be the insufficient accuracy of some assumptions in the FEA model.

\section{Conclusions}

This paper presents an investigation into the edge chipping during RUM of ceramics. A possible solution to reduce the edge chipping thickness was proposed based on FEA simulations and then validated by experiments. The main conclusions are:

1. As the cutting depth increases, the maximum values of the maximum normal stress and the von Mises stress increase.

2. The effects of pretightening load on the maximum values of the maximum normal stress and the von Mises stress are not significant.

3. There exists a critical support length. As the support length increases before reaching the critical length, the maximum values of the maximum normal stress and the von Mises stress decrease slightly. When the support length exceeds the critical length, there are sharp decreases in the maximum values of the maximum normal stress and the von Mises stress.

4. The edge chipping thickness can be reduced by increasing the support length. 
The results of this study have indicated a practical way to reduce or eliminate the edge chipping in rotary ultrasonic machining of ceramics: the diameter of the blind hole in the fixture underneath the workpiece should be as small as possible (as long as it can still receive the machined rod).

\section{Acknowledgements}

This work was supported in part by the Society of Manufacturing Engineers through a research initiation grant and by the Advanced Manufacturing Institute at Kansas State University. The authors gratefully extend their acknowledgements to Mr. Costa Sideridis at Ferro-Ceramic Grinding, Inc., for supplying the ceramic workpieces; Mr. Bruno Renzi at N.B.R. Diamond tool Corp. for supplying the diamond core drill; Mr. Timothy Deines in the Industrial and Manufacturing Systems Engineering Department of Kansas State University for his assistance in designing and fabricating the fixture; Professor Youqi Wang, Ms. Yuyang Miao, and Mr. Gruangming Zhou in the Mechanical and Nuclear Engineering Department of Kansas State University for their assistance in measurement of chipping thickness by a digital microscope.

\section{References}


[1] S. Jahanmir, L.K. Ives, A.W. Ruff, M.B. Peterson, Ceramic machining: assessment of current practice and research needs in the United States, NIST Special Publication 834, 1992.

[2] D. Prabhakar, Machining advanced ceramic materials using rotary ultrasonic machining process, M.S. Thesis, University of Illinois at Urbana-Champaign, 1992.

[3] D.P. Stinton, Assessment of the state of the art in machining and surface preparation of ceramics, ORNL/TM Report 10791, Oak Ridge National Laboratory, Tennessee, 1988.

[4] P. Legge, Ultrasonic drilling of ceramics, Industrial Diamond Review 24 (278) (1964) 2024.

[5] P. Legge, Machining without abrasive slurry, Ultrasonics July (1966) 157-162.

[6] Z.J. Pei, Rotary ultrasonic machining of ceramics: characterization and extensions, Ph.D. Thesis, University of Illinois at Urbana-Champaign, 1995.

[7] Z.J. Pei, P.M. Ferreira, M. Haselkorn, Plastic flow in rotary ultrasonic machining of ceramics, Journal of Materials Processing Technology 48 (1-4) (1995) 771-777.

[8] D. Prabhakar, Z.J. Pei, P.M. Ferreira, M. Haselkorn, A theoretical model for predicting material removal rates in rotary ultrasonic machining of ceramics, Transactions of the North American Manufacturing Research Institution of SME 21 (1993) 167-172.

[9] Z.J. Pei, P.M. Ferreira, Modeling of ductile mode material removal in rotary ultrasonic machining, International Journal of Machine Tools and Manufacture 38 (10-11) (1998) $1399-1418$.

[10] G. Spur, S.E. Holl, Material removal mechanisms during ultrasonic assisted grinding, Production Engineering 4 (2) (1997) 9-14. 
[11] W.M. Zeng, Z.C. Li, Z.J. Pei, C. Treadwell, Experimental observation of tool wear in rotary ultrasonic machining of advanced ceramics, International Journal of Machine Tools and Manufacture 45 (12-13) (2005) 1468-1473.

[12] P.G. Petrukha, et al., Ultrasonic diamond drilling of deep holes in brittle materials, Russian Engineering Journal 50 (10) (1970) 70-74.

[13] G. Spur, E. Uhlmann, S.E. Holl, N.A. Daus, Influences on surface and subsurface during ultrasonic assisted grinding of advanced ceramics, in: Proceedings of the $14^{\text {th }}$ Annual Meeting, the American Society for Precision Engineering, Monterey, CA, USA, Oct 31Nov 5, 1999, pp. 481-484.

[14] M. Kubota, Y. Tamura, N. Shimamura, Ultrasonic machining with a diamond impregnated tool, Bulletin Japan Society of Precision Engineering 11 (3) (1997) 127-132.

[15] W.M. Zeng, Z.C. Li, Z.J. Pei, C. Treadwell, Experimental investigation into rotary ultrasonic machining of alumina, in: CD-ROM Proceedings of ASME International Mechanical Engineering Congress and Exposition, Anaheim, CA, USA, Nov 13-19, 2004.

[16] A.I. Markov, I.D. Ustinov, A study of the ultrasonic diamond drilling of non-metallic materials, Industrial Diamond Review March (1972) 97-99.

[17] A.I. Markov, et al., Ultrasonic drilling and milling of hard non-metallic materials with diamond tools, Machine and Tooling 48 (9) (1977) 45-47.

[18] Z.J. Pei, P.M. Ferreira, S.G. Kapoor, M. Haselkorn, Rotary ultrasonic machining for face milling of ceramics, International Journal of Machine Tools and Manufacture 35 (7) (1995) 1033-1046.

[19] Z.J. Pei, P.M. Ferreira, An experimental investigation of rotary ultrasonic face milling, International Journal of Machine Tools and Manufacture 39 (8) (1999) 1327-1344. 
[20] N. Khanna, Z.J. Pei, P.M. Ferreira, An experimental investigation of rotary ultrasonic grinding of ceramics disk, Transactions of the North American Manufacturing Research Institution of SME 23 (1995) 67-72.

[21] E. Uhlmann, G. Spur, S.E. Holl, Machining of complex contours by ultrasonic assisted grinding, Technical Paper of Society of Manufacturing Engineers MR99-284 (1999) 1-13.

[22] G. Ya, H.W. Qin., Y.W. Xu, Y.S. Zhang, An experimental investigation on rotary ultrasonic machining, Key Engineering Materials 202-203 (2001) 277-280.

[23] Z.C. Li, Y. Jiao, T.W. Deines, Z.J. Pei, C. Treadwell, Rotary ultrasonic machining of ceramic matrix composites: feasibility study and designed experiments, International Journal of Machine Tools and Manufacturing 45 (12-13) (2005) 1402-1411.

[24] Z.C. Li, Z.J. Pei, W.M. Zeng, P. Kwon, C. Treadwell, Preliminary experimental study of rotary ultrasonic machining on zirconia toughened alumina, Transactions of the North American Manufacturing Research Institution of SME 33 (2005) 89-96.

[25] T.B. Thoe, D.K. Aspinwall, M.L.H. Wise, Review on ultrasonic machining, International Journal of Machine Tools and Manufacture 38 (4) (1998) 239-255.

[26] G. Spur, E. Uhlmann, S.E. Holl, Ultrasonic assisted grinding of ceramics, Industrial Ceramics 21 (3) (2001) 177-181.

[27] Z.J. Pei, N. Khanna, P.M. Ferreira, An investigation into rotary ultrasonic machining of structural ceramics: a review, Ceramic Engineering and Science Proceedings 16 (1) (1995) 259-278.

[28] N.K. Jain, V.K. Jain, Modeling of material removal in mechanical type advanced machining processes: a state-of-art review, International Journal of Machine Tools and Manufacture 41 (11) (2001) 1573-1635. 
[29] Y. Jiao, W.J. Liu, Z.J. Pei, X.J. Xin, C. Treadwell, Study on edge chipping in rotary ultrasonic machining on ceramics: an integration of designed experiment and FEM analysis, Journal of Manufacturing Science and Engineering 127 (4) (2005).

[30] Z.C. Li, Liang-wu Cai, Z.J. Pei, C. Treadwell, Finite element simulation of rotary ultrasonic machining for advanced ceramics, in: CD-ROM Proceedings of ASME International Mechanical Engineering Congress and Exposition, Anaheim, CA, USA, Nov 13-19, 2004.

[31] S. Ng, D. Le, S. Tucker, G. Zhang, Control of machining induced edge chipping on glass ceramics, in: Proceedings of the 1996 ASME International Mechanical Engineering Congress and Exposition, Manufacturing Engineering Division, MED(4), Atlanta, GA, USA, Nov 17-22, 1996, pp. 229-236.

[32] O. Yoshifumi, M. Tetsuo, S. Minoru, Chipping in high precision slot grinding of Mn- $\mathrm{Zn}$ ferrite, Annals of the CIRP 44 (1) (1995) 273-277.

[33] W.C. Chiu, M.D. Thouless, W.J. Endres, An analysis of chipping in brittle materials, International Journal of Fracture 90 (4) (1998) 287-298.

[34] Y.Q. Cao, Failure analysis of exit edges in ceramic machining using finite element analysis, Engineering Failure Analysis 8 (4) (2001) 325-338.

[35] J.M. Whitney and R.J. Nuismer, Stress fracture criteria for laminated composites containing stress concentration, Journal of Composite Materials 8 (3) (1974) 253-265.

[36] R.O. Ritchie, J.F. Knott, J.R. Rice, On the relationship between critical tensile stress and fracture toughness in mild steel, Journal of the Mechanics and Physics of Solids 21 (6) (1973) 395-410. 
[37] D. Walter, Pilkey Peterson's stress concentration factors, Second edition, John Wiley \& Sons, Inc., New York, NY, 1997. 